V.I. Milykh

\title{
A TURBO-GENERATOR DESIGN SYNTHESIS BASED ON THE NUMERICAL-FIELD CALCULATIONS AT VARYING THE NUMBER OF STATOR SLOTS
}

\begin{abstract}
Purpose. The work is dedicated to the presentation of the principle of construction and implementation of an automated synthesis system of the turbo-generator (TG) electromagnetic system in the case of its modernization. This is done on the example of changing the number of the stator core slots. Methodology. The basis of the synthesis is a TG basic construction. Its structure includes the mathematical and physical-geometrical models, as well as the calculation model for the FEMM software environment, providing the numerical calculations of the magnetic fields and electromagnetic parameters of TG. The mathematical model links the changing and basic dimensions and parameters of the electromagnetic system, provided that the TG power parameters are ensured. The physical-geometrical model is the geometric mapping of the electromagnetic system with the specified physical properties of its elements. This model converts the TG electromagnetic system in a calculation model for the FEMM program. Results. Testing of the created synthesis system is carried out on the example of the $340 \mathrm{MW}$ TG. The geometric, electromagnetic and power parameters of its basic construction and its new variants at the different numbers of the stator slots are compared. The harmonic analysis of the temporal function of the stator winding EMF is also made for the variants being compared. Originality. The mathematical model, relating the new and base parameters of TG at the changing of the number of the stator slots is created. A Lua script, providing the numerical-field calculations of the TG electromagnetic parameters in the FEMM software environment is worked out. Construction of the constructive and calculation models, the numerical-field calculations and delivery of results are performed by a computer automatically, that ensures high efficiency of the TG design process. Practical value. The considered version of the TG modernization on the example of changing the number of the stator core slots provided an opportunity for the presentation of the principle of construction and implementation of design synthesis system. For the practical use in the TG designing process, the developed and presented system can be more detailed with specifying the individual components of the mathematical model and expanded for varying other parameters of TG and optimizing its design. References 11, tables 2, figures 7 .
\end{abstract}

Key words: turbo-generator, modernization, design synthesis, mathematical model, Lua script, FEMM program, numerical-field calculations, electromagnetic parameters.

Представлен пример проектного синтеза электромагнитной системы турбогенератора (ТГ) при его модернизации. Создана математическая модель, связывающая новые и базовые параметры ТГ при изменении числа пазов статора. Разработан скрипт Lиа, обеспечивающий численно-полевые расчеты электромагнитных параметров ТГ в программной среде ҒЕММ. Построение конструктивной и расчетной моделей, численно-полевые расчеты и выдача результатов выполняются компьютером автоматически, что обеспечивает высокую эффективность процесса проектирования ТГ. Апробация системы синтеза проведена на примере ТГ мощностью 340 МВт. Библ. 11, табл. 2 , рис. 7.

Ключевые слова: турбогенератор, модернизация, проектный синтез, математическая модель, скрипт Luа, программа FЕММ, численно-полевые расчеты, электромагнитные параметры.

Introduction. Powerful turbo-generators (TG) are the most complicated, expensive and effective in operation electric machines [1]. Design and the subsequent creation of new models take months and even years.

Therefore, the process of improving the TG is often reduced to modernize their samples after long test operation [2]. At the same time seeking to improve the parameters of the TG with minimum changes as the global innovations in the complex can lead to unpredictable consequences and require long experimental refinement which requires large capital investments.

One option to speed up the modernization of TG is reduction of terms of computational and design works. They require a significant amount of time due to the complexity of classical methods of calculation as such because of the complexity of TG themselves. These methods are often adapted to specific design elements of standard sizes and need to be improved after their changes.

Numerical methods for calculating magnetic fields $[3,4]$ coupled with high-speed computers and efficient software provide new opportunities for improving the design system of the TG. This contributed to the novelty of the results provided, as an example of created on this basis an automated design synthesis system of the TG electromagnetic system in the case of their modernization at the change of certain key elements of the design is considered.

The goal of the work. The work is dedicated to the presentation of the principle of construction and implementation of an automated system of electromagnetic TG system synthesis in the case of its modernization that is being done on the example of changing the number of slots of the stator core.

Structure of synthesis is based on the basic design of the TG available and includes a mathematical model, a physical and geometrical model, a calculation model in conjunction with the program environment FEMM [5] which provides the numerical calculations of the magnetic field and electromagnetic parameters of the TG. The mathematical model relates the changing sizes and parameters of the electromagnetic system with its basic dimensions and parameters with the condition for the output power parameters of the TG. Physical and geometric model is a geometric mapping of the electromagnetic system with given properties of its components - the windings and cores. This model converts the electromagnetic system of the TG and the results of the mathematical model operation to the calculation model for the FEMM program. 
Creation of the physical and geometric model, its transformation into a calculation model, providing the FEMM program operation, the definition of the electromagnetic and power parameters based on numerical calculation of the magnetic field, output results of the synthesis of the updated TG electromagnetic system to a text file - all is done automatically by the control program written in the Lua language integrated in the FEMM [5].

Universalism of created models of available and developed software is that they are adapted to the typical structural shapes of $\mathrm{TG}$ as a whole and their elements. Numerical methods for the calculation of the magnetic field remove restrictions on the account of real constructive shapes of electric machines as a whole and their elements, on account of the magnetic saturation.

Largely developed software is based on investigations that have presented earlier in papers by the author [4, 6-10] and others.

Object of investigations. Demonstration of calculation results is carried out on a three-phase TG [2] the basic electromagnetic system of which is shown in Fig. 1. It has a rated: power $P_{N}=340 \mathrm{MW}$; phase voltage $U_{s N}=11547 \mathrm{~V}$ and current $I_{s N}=11547 \mathrm{~A}$; power factor $\cos \varphi_{s N}=0.85$; frequency $f_{s}=50 \mathrm{~Hz}$. Its number of pole pairs $p=1$; active length $l_{a}=5.308 \mathrm{~m}$; non-magnetic gap $\delta=77.5$ $\mathrm{mm}$; radius of the rotor surface $r_{r e}=0.56 \mathrm{~m}$; number of turns of its phase winding $N_{s}=10$, relative shortening $\beta_{s}=0.8$; number of effective conductors of the stator winding rod $N_{c s}=1$; number of turns of the rotor winding $N_{r}=126$.

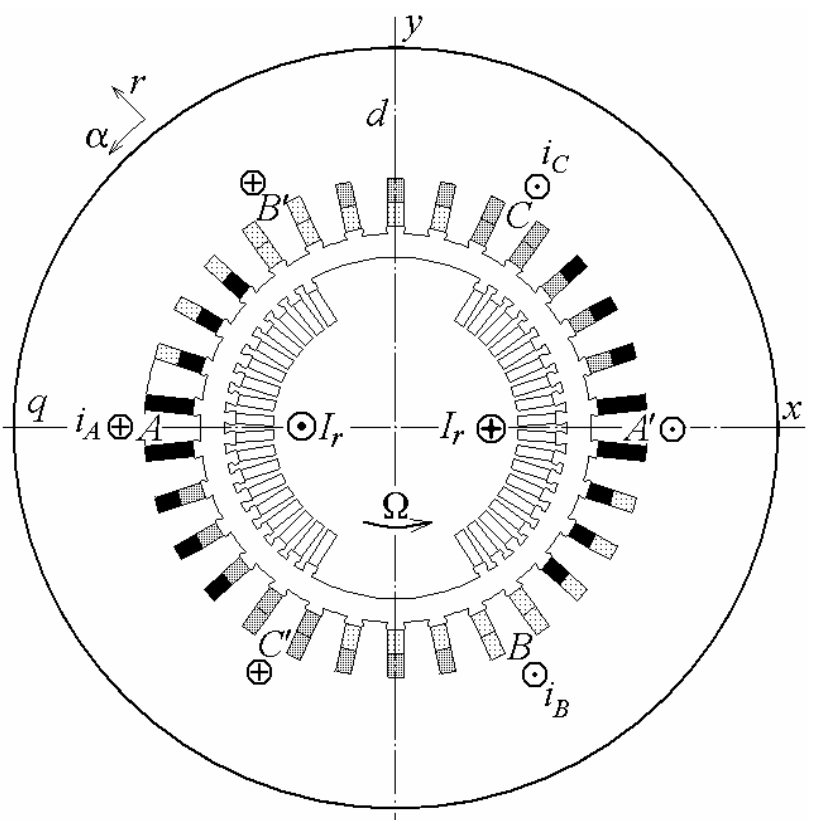

Fig. 1. Calculation model of the turbo-generator electromagnetic system

The basic values of the TG conserved in its modernization. Fig. 2 shows the TG structure with the indication of main dimensions of the cores of the stator and rotor. Taking into account the decisive role in the formation of the magnetic fields of the tooth-slot stator structure, it is shows by fragments with required dimensions marked in Fig. 3.

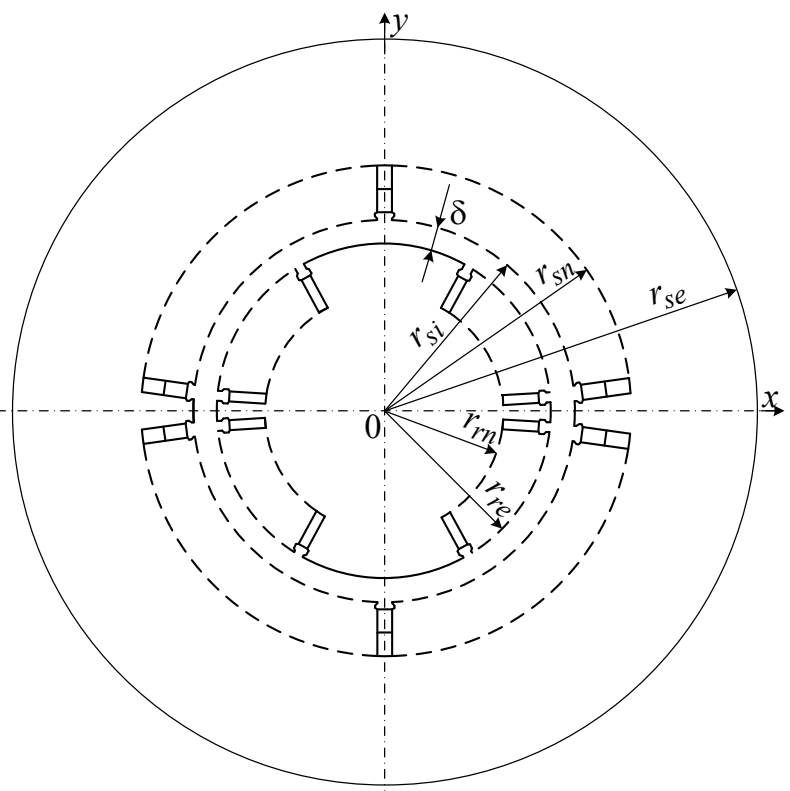

Fig. 2. Geometrical model of the turbo-generator

In order to in visualized form evaluate changes in the TG at the change of the number of stator slots, the presented TG output parameters are reserved: power, phase voltage and current, power factor. Also given in the long history of the TG design values of magnetic field strength in the gap, teeth and the back of the stator core as well as a gap characterized for the $\mathrm{TG}$ of corresponding power level are conserved.

Assuming the continuation of the stator current and the distributed current density in the conductors of its winding, sections of its rods must be preserved. Since the stator winding voltage is conserved, the insulating gaps in the slot are conserved, too (Fig. 3).

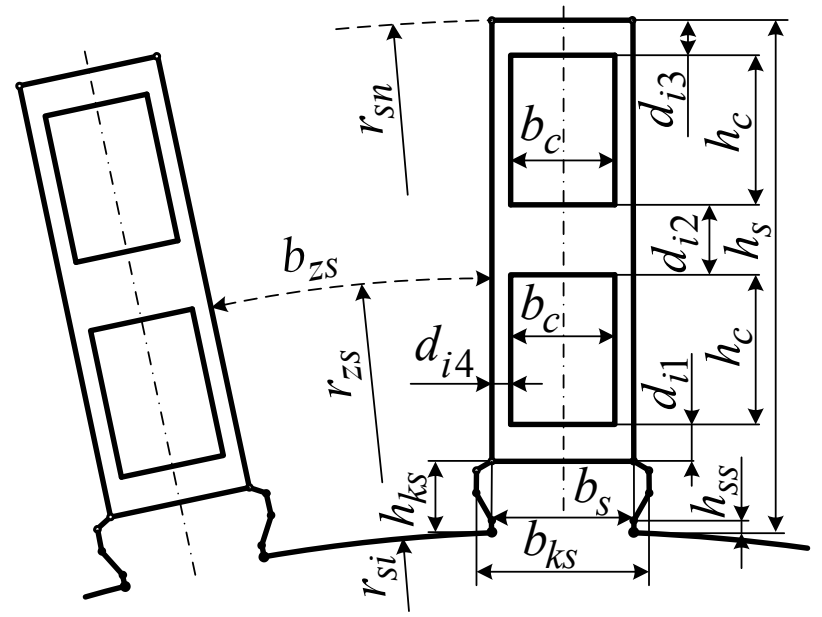

Fig. 3. Tooth-slot structure of the stator

When conserving the TG voltage, EMF of the phase stator winding should be conserved, too

$$
E_{s}=\pi \sqrt{2} \cdot f_{s} \cdot N_{s} \cdot \Phi_{s} \cdot K_{W s},
$$

where $\Phi_{s}$ is the magnetic flux in the gap; $K_{W s}$ is the stator winding factor.

For convenience, hereinafter we refer to the same indications of the same base and new values but for the first ones the letter $b$ in the indexes is added everywhere. 
Stator rods are characterized by their height $h_{c}$ and width $b_{c}$, the surrounding insulation in the slots - by thicknesses $d_{i 1}, d_{i 2}, d_{i 3}$ and $d_{i 4}$. In the basic design of the cross-sectional area of the stator winding $\operatorname{rod} S_{c b}=h_{c b} \cdot b_{c b}$. Taking into account the conditions set, at varying of $h_{c}$ and $b_{c}$ the following must be provided: $h_{c} \cdot b_{c}=S_{c b}$.

This variation accompanies the change in the size of the stator slots - their height $h_{s}$ and width $b_{s}$. Here, we must preserve the height of the spline $h_{s s}$ and the depth of the wedge $h_{k s}$ as well as two-way wedge recess in the wall of the slot $d_{k s}=b_{k s b}-b_{s b}$. The width of the grooves under the wedge should change and be $d_{k s}=b_{k s b}-b_{s b}$.

Note that in the basic design the following conditions must be satisfied: $b_{c}=b_{s}-2 d_{i 4} ; h_{c}=\left(h_{s}-d_{h s}\right) / 2$, where the constant addition by the height of the stator slot

$$
d_{h s}=h_{k s}+d_{i 1}+d_{i 2}+d_{i 3} \text {. }
$$

Mathematical model of the TG electromagnetic system synthesis.

First of all, we consider what changes need to occur in the stator and its slot and when the number of its slots is changed from the base value $Q_{s b}$ to the new one $Q_{s}$ which will be characterized by the coefficient of change in the number of stator slots:

$$
k_{Q s}=Q_{s} / Q_{s b} .
$$

We assume that the ratio of number of turns of the winding of the stator core of the base and the new design corresponds to the ratio of slots, i.e. $N_{s}=k_{Q s} N_{s b}$.

Then, from the condition of conservation of the EMF of the phase stator winding (1), the new value of the magnetic flux in the pole pitch $\Phi_{s}=\Phi_{s b} / k_{Q s}$.

By the magnetic flux, the magnetic flux density in the gap to the bore of the stator core (in this case, the average value) is determined

$$
B_{\delta}=\frac{\Phi_{s}}{\tau_{p} \cdot l_{a}},
$$

where we know the expression of the pole pitch on the radius of the stator bore $r_{s i}$ :

$$
\tau_{p}=\frac{\pi \cdot r_{s i}}{p}
$$

As already stated, the value of $B_{\delta}$ should remain as one of the fundamental quantities of TG and other electric machines.

The expression (3) includes two values, which, in principle, can be changed to conserve in the TG the previous value $B_{\delta}$, namely, the active length $l_{a}$ and the radius of the stator bore $r_{s i}$.

In this paper we restrict ourselves to the second option - to change the radius of the stator bore $r_{s i}$ as more complicated in the analysis. Active length $l_{a}$ is preserved such it was in the TG basic design.

Modernization of the TG electromagnetic system with changing the radius of the bore of the stator core. From a combination of the above relations a new value of this radius is obtained

$$
r_{s i}=r_{s i b} / k_{Q s} \text {. }
$$

To preserve the value of the magnetic flux density in the teeth of the stator core with the new number of slots, respectively the total width of the teeth changes

$$
b_{z s s}=b_{z s s b} / k_{Q s},
$$

Basic total width of all the stator teeth in their average radius of location $r_{z s b}$ (Fig. 3)

$$
b_{z s s b}=2 \cdot \pi \cdot r_{z s b}-b_{s b} \cdot Q_{s b},
$$

where $r_{z s b}=r_{s i b}+h_{s b} / 2 ; r_{s i b}$ is the radius of the bore of the stator core; $h_{s b}$ is the its slot height.

With the new value of the radius $r_{s i}$ by (5), we carry out a number of preparatory transformations of TG stator parameters for the new number of its teeth $Q_{s}$ in order to obtain the new value of the average radius of stator teeth $r_{z s}$, and then the other quantities.

The width of the new slot at the new value $Q_{s}$

$$
b_{s}=\frac{2 \cdot \pi \cdot r_{z s}-b_{z s s}}{Q_{s}} .
$$

The width and height of the stator winding rod

$$
b_{c}=b_{s}-2 \cdot d_{i 4} ; \quad h_{c}=S_{c b} / b_{c} .
$$

The height of the slot

$$
h_{s}=2 h_{c}+d_{h s} .
$$

For expressing the average radius of the tooth-slot structure we make substitutions based on relationships of written values above:

$$
\begin{gathered}
r_{z s}=r_{s i}+h_{s} / 2=r_{s i}+\left(2 h_{c}+d_{h s}\right) / 2=r_{s i}+h_{c}+d_{h s} / 2= \\
=r_{s i}+S_{c b} / b_{c}+d_{h s} / 2=r_{s i}+S_{c b} /\left(b_{s}-2 d_{i 4}\right)+d_{h s} / 2= \\
=r_{s i}+\frac{S_{c b}}{\frac{2 \cdot \pi \cdot r_{z s}-b_{z s s}}{Q_{s}}-2 \cdot d_{i 4}}+\frac{d_{h s}}{2}=e+\frac{Q_{s} S_{c b}}{2 \cdot \pi \cdot r_{z s}-d},
\end{gathered}
$$

where the notations are introduced for brevity $d=b_{z s s}+2 \cdot d_{i 4} \cdot Q_{s} ; e=\left(r_{s i}+d_{h s} / 2\right)$.

In fact, an equation is obtained from which, after incremental transformations we obtain the quadratic equation with respect to $r_{z s}$ :

$$
\left.r_{z s}^{2}-r_{z s}[d /(2 \cdot \pi)+e)\right]+\left[d e-S_{c b} \cdot Q_{s}\right] /(2 \cdot \pi)=0 .
$$

Its solution gives two roots, the meaning of which has an option with a plus sign before the radical:

$$
r_{z s}=-\frac{b}{2} \pm \sqrt{\frac{b^{2}}{4}-c},
$$

where $b=-e-d /(2 \cdot \pi) ; c=\left(d \cdot e-S_{c b} \cdot Q_{s}\right) /(2 \cdot \pi)$.

After obtaining $r_{z s}$ we determine for the new TG design values $b_{s}, b_{c}, h_{c}, h_{s}$ by (8)-(10).

Besides, we obtain the new values of the width of the stator wedge

stator core backrest height

$$
b_{k s}=b_{s}+d_{k s},
$$

$$
h_{a s}=h_{a s b} / k_{Q s},
$$

outer radius of the stator core

$$
r_{s e}=r_{s i}+h_{s}+h_{a s}
$$

number of serial turns of the two-layer stator windings is verified

$$
N_{s}=N_{c s} \cdot Q_{s} / m_{s},
$$

where $N_{c s}$ is the number of effective conductors in the rod; $m_{s}$ is the number of TG phases.

In the process of calculating TG electromagnetic parameters we use stator phase winding active resistance $R_{s}=R_{s b} \cdot k_{Q s}$ and reactance of frontal scattering $X_{v}=X_{v b} \cdot k_{Q s}^{2}[4,7]$ which are recalculated for the changes in the number of turns (16) by the same quanti- 
ties of the basic model.

With the change of the radius of the bore of the stator core it is necessary to correct the rotor structure (Fig. 2). In this regard, we consider two options: retaining and changing its dimensions of its slots which are separately designated in Fig. 4.

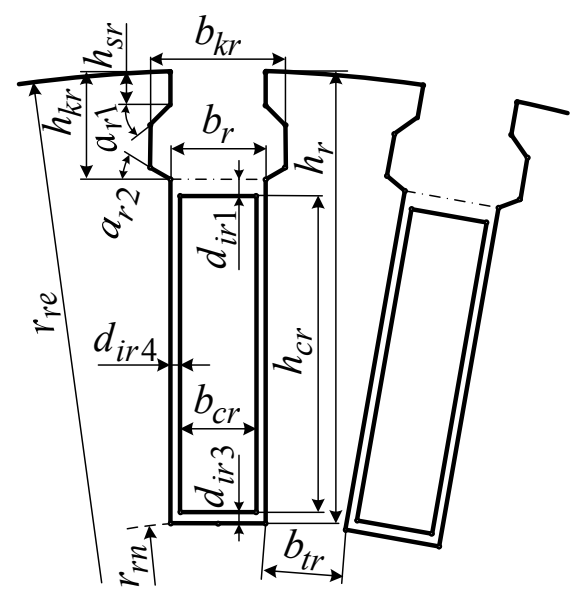

Fig. 4. Tooth-slot structure of the rotor

Correction of the rotor with maintaining its slots dimensions. With the new value of the radius of the bore of the stator core, the new radius of the rotor surface

$$
r_{r e}=r_{s i}-\delta \text {. }
$$

Therefore, correction of the number of rotor slots is need so as not to reduce the critical values of a rotor core - the width of the base of the rotor teeth

$$
b_{t r}=\frac{2 \cdot \pi \cdot r_{r n}}{Q_{r u}}-b_{r},
$$

where $Q_{r u}$ is the conditionally total number of rotor slots; $b_{r}$ is the rotor slot width; $r_{r n}=r_{r e}-h_{r}$ is the location radius of the rotor teeth base (Fig. 4).

When choosing the number of actual rotor slots $Q_{r}$ we conserve about the filling ratio of the rotor surface by the slots

$$
k_{Q r}=Q_{r} / Q_{r u}
$$

By these formulas (18), (19) for the base version of the TG we must take basic values $Q_{r u b}, Q_{r b}, b_{r b}, h_{r b}$, and then we obtain the values of the parameters $k_{Q r b}, b_{t r b}$ which further by varying the rotor sizes should be about conserved.

To transform the rotor design the following formulas are used.

New conditionally total number of rotor slots

$$
Q_{r u}=4 \cdot \operatorname{ceil}\left(\frac{0,5 \cdot \pi \cdot r_{r n}}{b_{r b}+b_{t r b}}-0,99\right),
$$

where the symbol ceil means rounded to the nearest whole number in the direction of greater value of the argument in parentheses.

The new number of coiled rotor slots

$$
Q_{r}=4 \cdot \operatorname{ceil}\left(0,25 \cdot Q_{r u} \cdot k_{Q r b}-0.99\right) .
$$

Number of serial turns of the rotor winding

$$
N_{r}=N_{c r} \cdot Q_{r} / 2 \text {, }
$$

where $N_{c r}$ is the number of effective conductors in the rotor slot, for the base variant it was $N_{c r b}=2 N_{r b} / Q_{r b}$.
Correction of the rotor with a change in its slots dimensions. For more detailed correction of the rotor design we can change the basic dimensions of its slot (Fig. 4).

At the correction of the rotor we conserve:

- cross-sectional area of the rotor winding rod

$$
S_{c r b}=h_{c r b} \cdot b_{c r b}
$$

where $h_{c r b}, b_{c r b}$ are the height and width of its winding rod;

- $\quad$ insulation gaps in the slot $d_{i r 1}, d_{i r 3}$ and $d_{i r 4}$, height of the wedge with spline $h_{k r}$;

- constant addition to the height of the rotor rod

$$
d_{h r}=h_{k r}+d_{i r 1}+d_{i r 3} \text {; }
$$

- two-side wedge deepening to the slot wall $d_{k r}=b_{k r}$ $b_{r b}$, where $b_{r b}$ is the width of the rotor base slot;

- width of the base of the rotor teeth $b_{t r b}$ (18);

- base filling factor of the surface of the rotor slots $k_{Q r b}$ determined by (19).

To keep the magnetic flux density in the base of the rotor teeth at the change of the number of stator slots, we change the radius of the location of the bottom of rotor slots proportionally to the magnetic flux change

$$
r_{r n}=r_{r n b} / k_{Q s} \text {. }
$$
and $Q_{r}$.

By formulas (21) and (22) we calculate values $Q_{r u}$

Keeping base value $b_{t r b}$ calculated by the formula like (18) we obtain new rotor slot width

$$
b_{r}=\frac{2 \cdot \pi \cdot r_{r n}}{Q_{r u}}-b_{t r b} .
$$

New values of rotor rod dimensions

$$
b_{c r}=b_{r}-2 \cdot d_{i r 4} ; h_{c r}=S_{c r b} / b_{c r} .
$$

New values of the slot height and width in the area under the wedge recess

$$
h_{r}=h_{c r}+d_{h r} ; b_{k r}=b_{r}+d_{k r} .
$$

The radii of the rotor surface and the stator core bore

$$
r_{r e}=r_{r n}+h_{r} ; r_{s i}=r_{r e}+\delta \text {. }
$$

Taking into account this new value of the radius $r_{s i}$ after that by (12) we calculate $r_{z s}$ for the new number of its teeth $Q_{s}$ and then other new values $h_{s}, b_{c}, h_{c}, b_{s}$ by the above formulas (12), (8) - (10) as well as the new values of the stator wedge width

$$
b_{k s}=b_{s}+d_{k s}
$$

outer radius of the stator core

$$
r_{s e}=r_{s i}+h_{s}+h_{a s} \text {. }
$$

As a result as before, the corresponding geometric model of the TG is formed

The presented set of formulas from (2) to (31) together with intermediate formulas and is a mathematical model of the TG electromagnetic system synthesis at the changing the number of its stator slots.

The structure of an automated synthesis system of the TG electromagnetic system. The basis for the use of a mathematical model, as stated above, are the parameters of the TG basic design and the new value of the number of stator slots. Since then the automated program complex synthesis of a new TG electromagnetic system synthesis begins. A block diagram of the synthesis program is shown in Fig. 5. 


\begin{tabular}{|c|c|}
\hline 1 & $\begin{array}{l}\text { Input from the text file the data of the base model and } \\
\text { necessary parameters of the new model of the TG }\end{array}$ \\
\hline & $\downarrow$ \\
\hline 2 & Calculation of the TG new model parameters \\
\hline & $\downarrow$ \\
\hline 3 & TG geometrical model building \\
\hline & $\downarrow$ \\
\hline 4 & TG physical model forming \\
\hline & $\downarrow$ \\
\hline 5 & $\begin{array}{l}\text { Iterative field calculations at the idle and short-circuit } \\
\text { modes to determine initial values of the TG excitation } \\
\text { parameters at the load mode }\end{array}$ \\
\hline & $\downarrow$ \\
\hline 6 & $\begin{array}{l}\text { Iterative field calculations at the load mode to determine } \\
\text { final TG excitation parameters }\end{array}$ \\
\hline & $\downarrow$ \\
\hline 7 & Final magnetic field calculation at the load mode \\
\hline & $\downarrow$ \\
\hline 8 & $\begin{array}{l}\text { Determination of the TG electromagnetic parameters } \\
\text { by the results of the numerical field calculation }\end{array}$ \\
\hline & $\downarrow$ \\
\hline 9 & Writing the calculation results to the text file \\
\hline & $\downarrow$ \\
\hline 10 & $\begin{array}{c}\text { Storage of the physical, geometrical and field models } \\
\text { of the TG in the computer file system }\end{array}$ \\
\hline
\end{tabular}

Fig. 5. A block diagram of the program for the TG electromagnetic system synthesis

All steps shown in Fig. 5 are organized and executed by the program written on the algorithmic language Luascript. The program starts and runs in the FEMM software environment [5] performing numerical calculation of the magnetic field by the finite element method.

The meaning of the blocks 1, 2, 7, 8, 9 and 10 in Fig. 5 , in principle, obvious by given in these texts. However, for the remaining blocks we give explanations.

The essence and software implementation of the blocks 3 and 4 are presented in [9]. In them on the base of the input and calculated information on the geometrical dimensions of TG the geometrical model of the TG is built as shown in Fig. 2, Fig. 3 and Fig. 4. For the parts of this model magnetic and current properties are defined - a physical model is formed. And in general a physical and geometric model of the TG for the magnetic field in the software environment FEMM is obtained.

Power parameters of the TG are set by values of power, phase voltage and current, power factor. And to achieve them in each new version of the TG we need to know the parameters of the excitation of the magnetic field at the load mode. These parameters include excitation current in the rotor winding $I_{r}$ and phase shift $\beta$ of the stator winding EMF relative to the rotor windings EMF.

Theory and principle of their determination are described in [7] and they are based on iterative calculations of magnetic fields at the idle, short-circuit and the load modes. All this is done in blocks 5 and 6 (Fig. 5), and software implementation is presented in [10]. Besides, in them necessary electromagnetic parameters of the TG are determined that corresponds to the block 8 in Fig. 5 in which also harmonic analysis of the angle function of the magnetic flux linkage the temporal function of EMF of the phase stator winding in accordance with the theory presented in [8] is carried out.

Results of operation of the software complex for the TG electromagnetic system synthesis.

First of all, the developed software system has been tested on the base model with the number of TG stator slots $Q_{s b}=30$. That is based on the basic model, the same one is synthesized. Next, the synthesis of new models with slot numbers $Q_{s}$ equal to 24 and 36 has been carried out. They are closest to basic model minimal and greater values of $Q_{s}$ taking into account that

$$
Q_{s}=2 \cdot p \cdot m_{s} \cdot q_{s}
$$

where the number of slots per pole and phase $q_{s}$ must be an integer.

Step of the stator winding by slots $y_{s}$ is calculated in the program on the condition of ensuring the coefficient of relative shortening $\beta_{s}$ nearest or equal to 0.833 which gives the most suitable harmonic structure of the stator winding EMF [1].

Each of the TG models with their values $Q_{s}$ is synthesized in two considered above rotor correction variants: 1) while maintaining its slot dimensions; 2) changing them. Further number of these options added to the values of the numbers of stator slots.

It should be noted that the calculation of one variant on a computer of sufficiently high level taken about 10 minutes, with the number of nodes of the finite element structure according to the variant was 30-40 thousand, the number of triangles 60-80 thousand.

A geometrical model of the TG base variant was already presented in Fig. 1 and is repeated in Fig. 6 together with the calculated magnetic field distribution. Models of synthesized electromagnetic systems are shown in Fig. 7 - each one by fourth cross-section with the corresponding parts of the picture of the magnetic field at the load mode.

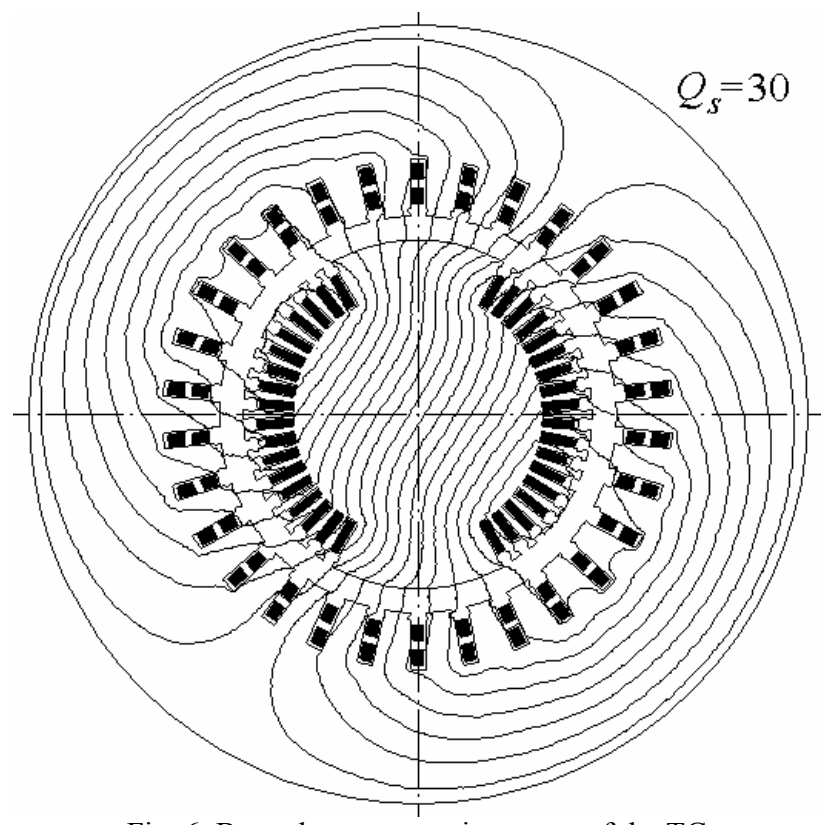

Fig. 6. Base electromagnetic system of the TG 


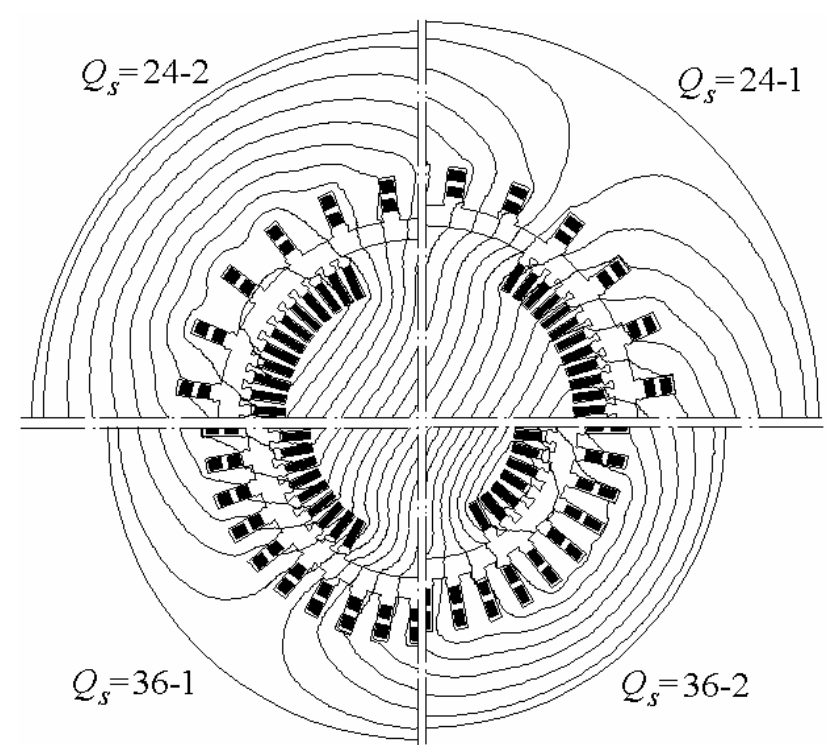

Fig. 7. Variants of the TG electromagnetic system

In the numeric form part of information about these models is presented in Table 1 .

Table 1

Parameters of the TG electromagnetic system in various its variants

\begin{tabular}{|c|c|c|c|c|c|}
\hline$Q_{s}$ & $24-1$ & $24-2$ & 30 & $36-1$ & $36-2$ \\
\hline$y_{s}$ & 10 & 10 & 12 & 15 & 15 \\
\hline$\beta_{s}$ & 0.833 & 0.833 & 0.8 & 0.833 & 0.833 \\
\hline$Q_{r}$ & 48 & 48 & 36 & 36 & 36 \\
\hline$N_{r}$ & 168 & 168 & 126 & 126 & 98 \\
\hline$N_{s}$ & 8 & 8 & 10 & 12 & 12 \\
\hline$r_{s i}, \mathrm{~mm}$ & 797 & 749 & 637.5 & 637.50 & 570 \\
\hline$r_{s e}, \mathrm{~mm}$ & 1482 & 1451 & 1250 & 1167 & 1126 \\
\hline$h_{s}, \mathrm{~mm}$ & 148 & 165 & 183 & 171 & 199 \\
\hline$b_{s}, \mathrm{~mm}$ & 68.8 & 58.5 & 50.8 & 55.5 & 46.0 \\
\hline$h_{c}, \mathrm{~mm}$ & 36.1 & 44.4 & 53.5 & 47.6 & 61.4 \\
\hline$b_{c}, \mathrm{~mm}$ & 55.4 & 45.1 & 37.4 & 42.1 & 32.6 \\
\hline$h_{r}, \mathrm{~mm}$ & 160 & 171.5 & 160 & 160 & 158.7 \\
\hline$b_{r}, \mathrm{~mm}$ & 33,9 & 34. & 33.9 & 33.9 & 37.9 \\
\hline$I_{r o}, \mathrm{~A}$ & 715 & 840 & 1028 & 847 & 1269 \\
\hline$I_{r}, \mathrm{~A}$ & 1896 & 2121 & 3159 & 3419 & 5020 \\
\hline$\beta_{,} \mathrm{degree}$ & -158.56 & -156.98 & -160.42 & -166.13 & -162.78 \\
\hline$F_{r}, \mathrm{KA}$ & 319 & 356 & 398 & 431 & 492 \\
\hline$F_{s}, \mathrm{KA}$ & 196 & 196 & 245 & 294 & 294 \\
\hline$A W_{s}, \mathrm{KA}$ & 277 & 277 & 346 & 416 & 416 \\
\hline$k_{M m}$ & 1.748 & 1.820 & 1.712 & 1.548 & 1.666 \\
\hline$P_{e m s}, \mathrm{MW}$ & 343.5 & 340.9 & 341.2 & 342.3 & 342.1 \\
\hline$\Delta P_{r s}, \mathrm{KW}$ & 851 & 851 & 1064 & 1277 & 1277 \\
\hline$\Phi_{s o}, \mathrm{~Wb}$ & 1.339 & 1.328 & 1.102 & 0.920 & 0.919 \\
\hline$\Phi_{s}, \mathrm{~Wb}$ & 1.459 & 1.475 & 1.248 & 1.065 & 1.080 \\
\hline$B_{\delta}, \mathrm{T}$ & 1.309 & 1.224 & 1.306 & 1.139 & 1.260 \\
\hline$B_{z r}, \mathrm{~T}$ & 1.682 & 1.809 & 1.910 & 1.773 & 2.018 \\
\hline$B_{y r}, \mathrm{~T}$ & 1.393 & 1.597 & 1.771 & 1.563 & 1.978 \\
\hline$B_{z s}, \mathrm{~T}$ & 1.629 & 1.512 & 1.635 & 1.738 & 1.703 \\
\hline$B_{y s}, \mathrm{~T}$ & 1.604 & 1.607 & 1.639 & 1.699 & 1.668 \\
\hline & & & & & \\
\hline
\end{tabular}

Here, in addition to already represented values we present: $I_{r o}$ - rotor current at the idle mode; $F_{r}=N_{r} \cdot I_{r}$ EMF of the rotor winding under load; $F_{s}=1.5 \sqrt{2} \cdot I_{s} \cdot N_{s}$ EMF amplitude of the stator windings; $A W_{s}=m_{s} \cdot I_{s} \cdot N_{s}$ ampere-turns of the stator winding which in contrast to $F_{s}$ characterize not electromagnetic nature but just design filling of the winding like $F_{r} ; k_{M m}$ - TG overload capacity; $P_{e m s}$ - electromagnetic power determined by the electromagnetic torque; $\Delta P_{r s}$ - electric power loss in the stator winding; $\Phi_{s o}, \Phi_{s}$ - magnetic fluxes in the gap on the pole division at modes of idle and load; maximum values of the magnetic flux density at the load mode in the center points by parts of the magnetic system: $B_{\delta}$ - in the gap; Bzr, Byr - in the teeth and the yoke of the rotor core; $B_{z r}$, $B_{y r}$ - in the teeth and the yoke of the stator core.

In more detail the meaning and procedure for determining the values presented can be found in the works, which list is in [11].

Table 2 presents a harmonic composition of the temporal function of EMF of the phase winding which is determined in accordance with [8]. Here we present the amplitude of the first harmonic $E_{m, 1}$ in absolute terms, as well as the amplitudes of the odd harmonics with numbers $v$ - in relative form $E_{m, v,{ }^{*}}=E_{m, v} / E_{m, 1}$.

Table 2

Harmonic composition of the stator winding EMF at various variants of the TG electromagnetic system

\begin{tabular}{|c|c|c|c|c|c|}
\hline$Q_{s}$ & $24-1$ & $24-2$ & 30 & $36-1$ & $36-2$ \\
\hline$E_{m 1}, \mathrm{~V}$ & 16715 & 16715 & 16930 & 17198 & 17196 \\
\hline$E_{m 3^{*}}$ & 0.0564 & 0.1112 & 0.0647 & 0.0745 & 0.0719 \\
\hline$E_{m 5^{*}}$ & 0.0087 & 0.0044 & 0.0048 & 0.0125 & 0.0125 \\
\hline$E_{m 7^{*}}$ & 0.000 & 0.0024 & 0.0069 & 0.0024 & 0.0051 \\
\hline$E_{m 9^{*}}$ & 0.0038 & 0.000 & 0.0083 & 0.0061 & 0.0063 \\
\hline$E_{m 11^{*}}$ & 0.0205 & 0.0166 & 0.0192 & 0.0191 & 0.0221 \\
\hline$E_{m 13^{*}}$ & - & - & 0.0105 & 0.0181 & 0.0209 \\
\hline$E_{m 15^{*}}$ & - & - & - & 0.0024 & 0.0037 \\
\hline$E_{m 17^{*}}$ & - & - & - & - & 0.0052 \\
\hline$d_{\text {distE }}$ & 0.9982 & 0.9937 & 0.9976 & 0.9968 & 0.9968 \\
\hline
\end{tabular}

The total content of series is characterized by the distortion factor

$$
d_{\text {dist }}=\frac{E_{m, 1}}{\sqrt{\sum_{v=1,3,5, \ldots}^{N_{g}} E_{m, v}^{2}}},
$$

where $N_{g}$ is the number of accounted harmonics equal $Q_{s} / 2$.

This ratio (33) for «pure» sine wave is equal to one, and its reduction indicates increase the role of higher harmonics. Although, in principle, obtained harmonic compositions for considered options of the TG electromagnetic systems are quite acceptable in terms of quality of generated electricity, the more that the main higher harmonic - the third, which at the connection of the stator windings in a «star» in the three-phase system of line voltages theoretically disappears.

Presented in Tables data and models in Fig. 6, 7 give a clear picture of developments during the modernization of the TG electromagnetic system. However, their detailed analysis is beyond the scope of this paper. Their role is to demonstrate the capabilities and efficiency of the developed system of the TG electromagnetic system synthesis on the example of changing the number of slots of the stator core.

\section{Conclusions.}

1. A synthesis system for the TG electromagnetic system is made possible by numerical methods for calculat- 
ing magnetic fields in conjunction with high-speed computers and efficient software.

2. Considered variant of synthesis as an example of the TG modernization by changing the number of the stator core slots provided an opportunity for the implementation of principles of construction and implementation of the design synthesis system, in general, and can be, in particular, expanded for the possibility of variation and other parameters of the TG in order to optimize its design.

3. For the practical use in the design of TG the developed and presented synthesis system can be more detailed, specifying the individual components of the mathematical model at maintaining the principles of design and implementation of such a system.

\section{REFERENCES}

1. Izvekov V.I., Serihin N.A., Abramov A.I. Proektirovanie turbogeneratorov [Planning of turbogenerators]. Moscow, MEI Publ., 2005. 440 p. (Rus).

2. Yu.V. Zozulin, O.Ye. Antonov, V.M. Bychik, A.M. Borychevs'kyy, K.O. Kobzar, O.L. Livshyts', V.H. Rakohon, I.Kh Rohovyy, L.L. Khaymovych, Cherednyk V.I. Stvorennja novyh typiv ta modernizacija dijuchyh turbogeneratoriv dlja teplovyh elektrychnyh stancij [Creation of new types and modernization of the existing turbogenerators for the thermal electric stations]. Kharkiv, PF Kolehium Publ., 2011. 228 p. (Ukr).

3. Bianchi Nicola. Electrical Machine Analysis Using Finite Elements (Copyrighted Material). CRC Press, Taylor \& Francis Group, University of West Florida, 2005. 276 p.

4. Milykh V.I., Polyakova N.V. Determination of electromagnetic parameters of electric machines based on numerical calculations of magnetic field. Electrical engineering \& electromechanics, 2006, no.2, pp. 40-46. (Rus). doi: 10.20998/2074272X.2006.2.09.

5. Meeker D. Finite Element Method Magnetics. FEMM 4.232 bit 11 Oct 2010 Self-Installing Executable. Available at: www.femm.info/wiki/OldVersions (accessed 10 March 2014).
6. Milykh V.I., Polyakova N.V. A system of directions and phase relationships for electromagnetic parameters at numerical calculations of magnetic fields in a turbogenerator. Electrical engineering \& electromechanics, 2011, no.5, pp. 33-38. (Rus). doi: 10.20998/2074-272X.2011.5.07.

7. Milykh V.I., Polyakova N.V. Organization of numerical calculation of turbogenerator magnetic field under load with specified output parameters control. Electrical engineering \& electromechanics, 2012, no.1, pp. 36-41. (Rus). doi: 10.20998/2074-272X.2012.1.08.

8. Milykh V.I., Polyakova N.V. Harmonious analysis of electromagnetic sizes three-phase winding of stators of turbogenerator on basis classic and numeral field methods. Tekhnichna elektrodynamika, 2013, no.3, pp. 40-49. (Rus).

9. Milykh V.I., Polyakova N.V. Automated formation of calculation models of turbogenerators for software environment FEMM. Electrical engineering \& electromechanics, 2015, no.4, pp. 7-14. (Rus). doi: 10.20998/2074-272X.2015.4.02.

10. Milykh V.I., Polyakova N.V. Determination of electromagnetic parameters and phase relations in turbo-generators by the automated calculation of the magnetic field in the software environment FEMM. Electrical engineering \& electromechanics, 2016, no.1, pp. 26-32. (Rus). doi: 10.20998/2074-272X.2016.1.05. 11. Milykh V.I., Polyakova N.V. Numerically-field calculations of the electromagnetic parameters of turbogenerators. Bulletin of $N T U$ «KhPI». Series: "Electric machines and electromechanical energy conversion», 2014, no.38(1081), pp. 3-18. (Rus).

Received 18.08.2016

V.I. Milykh, Doctor of Technical Science, Professor,

National Technical University «Kharkiv Polytechnic Institute», 21, Kyrpychova Str., Kharkiv, 61002, Ukraine.

phone+38057 7076514, e-mail: mvikemkpi@gmail.com

\section{How to cite this article:}

Milykh V.I. A turbo-generator design synthesis based on the numerical-field calculations at varying the number of stator slots. Electrical engineering \& electromechanics, 2016, no.6, pp. 19-25. doi: 10.20998/2074-272X.2016.6.04. 